\title{
Single-Cell Characterization of Retrograde Signaling by Brain-Derived Neurotrophic Factor
}

\author{
Jason P. Magby, ${ }^{1}$ Caixia Bi, ${ }^{1}$ Zhe-Yu Chen, ${ }^{2}$ Francis S. Lee, ${ }^{2}$ and Mark R. Plummer ${ }^{1}$ \\ ${ }^{1}$ Department of Cell Biology and Neuroscience, Rutgers University, Piscataway, New Jersey 08854, and ${ }^{2}$ Department of Psychiatry, Weill Medical College of \\ Cornell University, New York, New York 10021
}

\begin{abstract}
Brain-derived neurotrophic factor (BDNF) is a key regulator of hippocampal synaptic plasticity in the developing and adult nervous system. It can be released from pyramidal neuron dendrites in an activity-dependent manner and has therefore been suggested to serve as a signal that provides the retrograde intercellular communication necessary for Hebbian plasticity and hippocampal-dependent learning. Although much has been learned about BDNF function by field stimulation of hippocampal neurons, it is not known whether moderate action potential-independent depolarization of single cells is capable of releasing sufficient BDNF to influence transmission at individual synapses. In this study, we show directly at the single-cell level that such modulation can occur. By using K-252a, anti-BDNF antibody, and interruption of regulated release, we confirm a model in which postsynaptic depolarization elicits calcium-dependent release of BDNF that diffuses retrogradely and enhances presynaptic transmitter release.
\end{abstract}

Key words: BDNF; neurosecretion; neurotrophin; synaptic communication; synaptic transmission; synaptogenesis

\section{Introduction}

In recent years, it has become clear that communication between neurons is bidirectional, with both axon terminals and dendrites capable of sending and receiving signals from their synaptic partners. There are two general categories of retrograde signaling that differ in their time courses and modes of action (Fitzsimonds and Poo, 1998; Ginty and Segal, 2002). One type is primarily trophic and involves long-distance transport of target-derived signals from distal terminals to the nucleus. The second is more local and rapid, involving activity-dependent release of factors from the postsynaptic neuron that bind to receptors on the presynaptic cell effecting changes ranging from rapid alterations in transmitter release to alterations in synaptic structure (Chao, 2003; Du and Poo, 2004; Schmidt, 2004).

There is substantial evidence that brain-derived neurotrophic factor (BDNF) participates in both types of retrograde signaling. It can be released from target cells and can induce endocytosis of its cognate receptor, trkB, which is then transported back to the soma (Du et al., 2003). There are also numerous studies showing that BDNF can elicit rapid (within minutes) presynaptic changes in synaptic activity (Lessmann, 1998; Lu and Gottschalk, 2000). For these types of synaptic plasticity, it is known that action potential firing can evoke BDNF release (Balkowiec and Katz, 2000; Hartmann et al., 2001), but it is not known whether moderate

Received June 22, 2006; revised Nov. 28, 2006; accepted Nov. 28, 2006.

This work was supported by National Institutes of Health Grants NS041310 and HD23315. We thank Dr. Robin L. Davis for a critical reading of this manuscript, Rosa Cortés for help with the transfections, and Qing Hsu for expert technical assistance.

Correspondence should be addressed to Dr. Mark R. Plummer, Department of Cell Biology and Neuroscience, Rutgers University, Nelson Laboratories, Busch Campus, 604 Allison Road, Piscataway, NJ 08854-8082. E-mail: mplummer@rci.rutgers.edu.

DOI:10.1523/JNEUROSCI.4576-06.2006

Copyright $\odot 2006$ Society for Neuroscience $\quad$ 0270-6474/06/2613531-06\$15.00/0 depolarization, of the type observed early during development (Ben-Ari, 2002), is also capable of inducing BDNF release. Moreover, it has not been fully shown whether BDNF actually fulfills the conditions necessary to qualify as a retrograde signaling molecule (Fitzsimonds and Poo, 1998), particularly at the single-cell level (Alger, 2002). To establish this point, the test criteria include the following: (1) induction of postsynaptic release from a single cell; (2) demonstration that the postsynaptic release elicits a change in presynaptic activity; and (3) confirmation that BDNF is the diffusible messenger by exogenous application, block with specific antagonists and scavengers, and inhibition of release. The goals of this study were to determine whether tonic postsynaptic depolarization can elicit BDNF release from embryonic hippocampal neurons and whether BDNF satisfies the formal criteria for a retrograde signaling molecule.

\section{Materials and Methods}

Tissue culture

Time-mated pregnant Sprague Dawley rats were killed by $\mathrm{CO}_{2}$ asphyxiation in accordance with institutional guidelines for the care and use of animals. Fetuses were removed by cesarean section and transferred to a sterile Petri dish with PBS. Fetal hippocampi were dissected from surrounding brain tissue, and meninges were completely removed. Hippocampi were dissociated by trypsinization, followed by trituration through fire-polished Pasteur pipettes. Neurons were plated in poly-D-lysine-coated $35 \mathrm{~mm}$ Nunc (Naperville, IL) dishes and maintained in serum-free medium (SFM). SFM was composed of a 1:1 mixture of Ham's F-12 and Eagle's MEM (Invitrogen, Gaithersburg, MD) supplemented with $25 \mu \mathrm{g} / \mathrm{ml}$ insulin, $100 \mu \mathrm{g} / \mathrm{ml}$ transferrin, $60 \mu \mathrm{M}$ putrescine, $20 \mathrm{~nm}$ progesterone, $30 \mathrm{~nm}$ selenium, and $6 \mathrm{mg} / \mathrm{ml}$ glucose. Cells were plated at a density at $4 \times 10^{5}$ cells $/ 35 \mathrm{~mm}$ dish and grown at $37^{\circ} \mathrm{C}$ in $5 \% \mathrm{CO}_{2}$.

\section{Electrophysiological recordings}

Whole-cell patch-clamp recordings were performed after 12-15 d in culture. Currents were recorded with an Axopatch 200 amplifier, digi- 
tized at $2.9 \mathrm{kHz}$, and filtered at $1 \mathrm{kHz}$. Data analysis programs were as used previously (Alder et al., 2005). The external bath solution [neuron recording solution (NRS)] consisted of (in mM) $1.67 \mathrm{CaCl}_{2}, 1 \mathrm{MgCl}_{2}, 5.36 \mathrm{KCl}, 137$ $\mathrm{NaCl}, 17$ glucose, 10 HEPES, and 13.15 sucrose. The pipette solution contained (in $\mathrm{mm}$ ) 105 Cs-methanesulfonate, $17.5 \mathrm{CsCl}, 10$ HEPES, 0.2 EGTA, $8 \mathrm{NaCl}, 2 \mathrm{Mg}$-ATP, $2 \mathrm{Na}_{2}$ ATP, $0.3 \mathrm{Na}_{3}$-GTP, and 20 phosphocreatinine. The $\mathrm{pH}$ of the internal solution was set to 7.3 with $\mathrm{CsOH}$. The typical range of pipette resistance was 3-5 M $\Omega$. To record mESPCs, NRS and BDNF perfusion solutions contained $1 \mu \mathrm{M}$ tetrodotoxin (TTX; Sigma, St. Louis, MO). Pyramidal-type cells were recorded in voltageclamp mode, and the membrane potential was as specified in the text.

\section{Event criteria}

Events were included for analysis if they possessed a minimum amplitude of $5 \mathrm{pA}$ or were $25 \%$ larger than baseline noise. Additional criteria included rapid rise, distinct peak, and monoexponential decay. Confirmation that events that satisfied these criteria were predominantly glutamatergic miniature EPSCs (mEPSCs) was obtained by perfusion of $\mathrm{CNQX}$ and AP-5. For the time-course analysis, a response was defined as a sustained increase in activity at least 2 SEs over baseline. Consistent with our previous work (Levine et al., 1995), the majority of recorded neurons under control conditions responded to depolarization of $-40 \mathrm{mV}$ with an increase in mEPSC frequency. The small number of cells that did not respond were assumed to be of a different neuronal subtype and were not included in the analysis.

\section{DNA constructs}

Viral vectors were derived from human immunodeficiency virus-based lentiviral backbones provided by Dr. K. Ressler (Emory University, Atlanta, GA). The lentivirus plasmid containing green fluorescent protein (GFP) is pWPT-GFP. The Box 1 and Box $2+3$ constructs consisted of BDNF encoding amino acids $19-43$ and $44-102$, respectively, fused to GFP and subcloned into the pWPT-GFP vector replacing the GFP fragment using the BamHI and SalI sites.

\section{Transfection}

Cells were transfected with the calcium phosphate method. For each construct, $4 \mu \mathrm{l}$ of $2 \mathrm{mM} \mathrm{CaCl}_{2} / 35 \mathrm{~mm}$ dish was combined in an Eppendorf tube with $3 \mu \mathrm{g}$ of DNA (total at $0.5 \mu \mathrm{g} / \mu \mathrm{l}$ ) and $20 \mu \mathrm{l}$ of sterile water. Thirty microliters of $2 \times \mathrm{HBS}$ (in mM: $274 \mathrm{NaCl}, 10 \mathrm{KCl}, 1.4 \mathrm{Na}_{2} \mathrm{HPO}_{4}$, 15 glucose, 42 HEPES) were added dropwise to each tube, and the mixture was kept in the dark for $30 \mathrm{~min}$ at room temperature. Neuron cultures were then washed two times with SFM, and a $30 \mu \mathrm{l}$ DNA mixture was added to each dish and placed back in the incubator for $20 \mathrm{~min}$. The cultures were again washed twice with SFM, after which $1.5 \mathrm{ml}$ of conditioned media was added before returning the cells to the incubator. Cells were transfected at 3-4 $\mathrm{d}$ in vitro and recorded $9 \mathrm{~d}$ later.

\section{Results}

The objective of this study was to assess BDNF release in response to moderate depolarization and to test in a formal way whether BDNF satisfied the criteria for a retrograde messenger. In particular, we examined the following: (1) depolarization-induced release of BDNF from a single postsynaptic neuron; (2) capability of released BDNF to diffuse to presynaptic neurons and modulate potential.

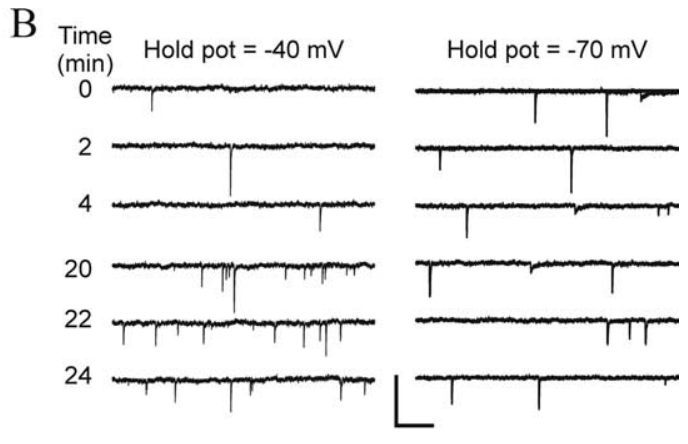

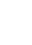

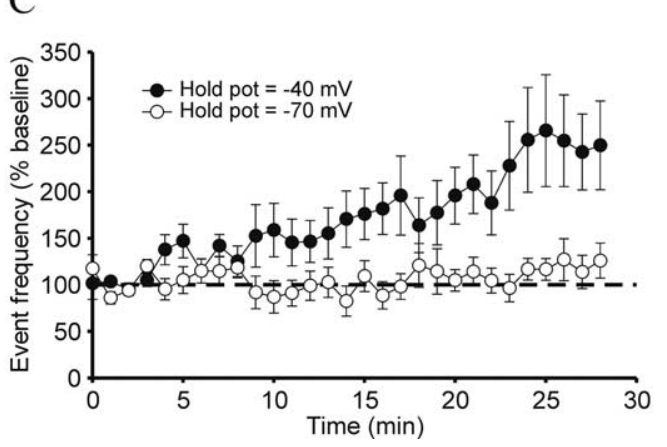

Figure 1. Postsynaptic depolarization elicits an increase in presynaptic release probability. $\boldsymbol{A}$, Hippocampal neurons in tissue Whole-cell patch-clamp recordings were made from pyramidal-like neurons. Presynaptic activity was assessed by moniwith the holding potential of $-70 \mathrm{mV}$ ( $p<0.05$, two-tailed Student's $t$ test). Error bars indicate \pm SEM. Hold pot, Holding

transmitter release; and (3) confirmation that BDNF is the diffusible messenger by recapitulating effects of depolarization with application of exogenous BDNF and by preventing effects of depolarization with BDNF-specific blocking compounds, and inhibition of regulated release of BDNF.

We addressed the first two criteria with whole-cell patchclamp recordings from cultured embryonic day 18 hippocampal neurons. When placed in culture and maintained for $>12 \mathrm{~d}$ in vitro, these neurons form a synaptic network that generates ongoing action potential activity. BDNF release from individual neurons was induced with direct depolarization of the cell being recorded from (Fig. 1A). Alteration in presynaptic activity was assessed by application of TTX, which allows recording of spontaneous mEPSCs in the cell being recorded from. The frequency of mEPSCs was then used as a measure of presynaptic release probability (Bouron, 2001). When depolarized to a membrane potential of $-40 \mathrm{mV},>85 \%$ of neurons recorded from (eight of nine) showed a gradual increase in mEPSC frequency (239 \pm $46 \%$ of baseline; $n=8$ ) (Fig. $1 B, C$ ). This increase in frequency was not simply the result of recording, because holding cells at the more negative potential of $-70 \mathrm{mV}$ did not elicit a similar increase in activity in any of the recorded cells $(112 \pm 13 \% ; n=7)$ (Fig. $1 B, C$ ). The data suggested that depolarization of the postsynaptic cell was sufficient to elicit dendritic release of BDNF, which then diffused to the terminals of the presynaptic neurons to alter presynaptic release probability.

To validate this hypothesis, as well as the third criterion above, we tested each critical step in the retrograde signaling process by 
A

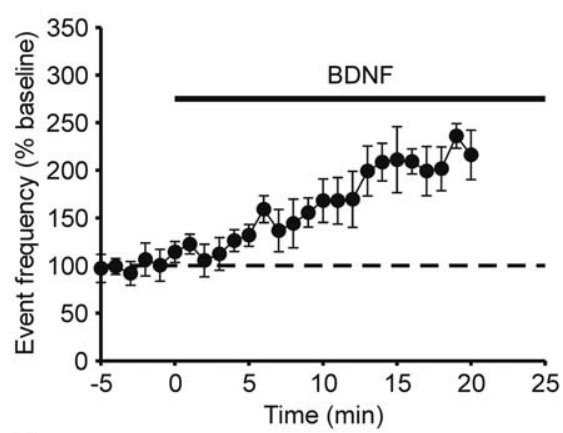

C

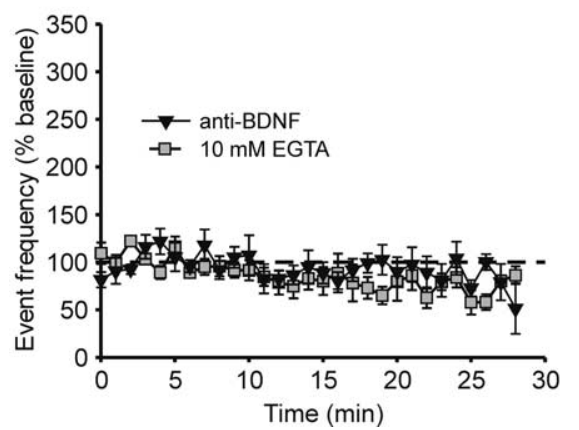

B

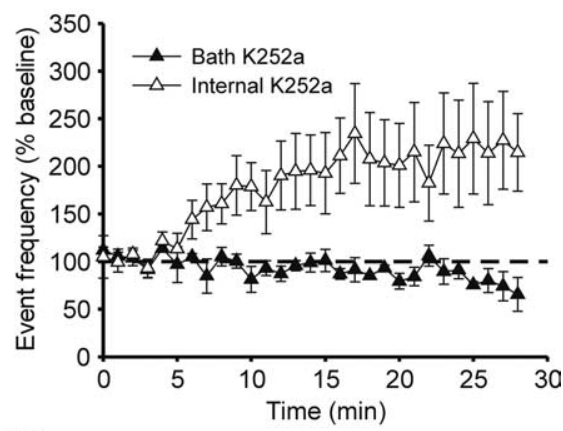

$\mathrm{D}$

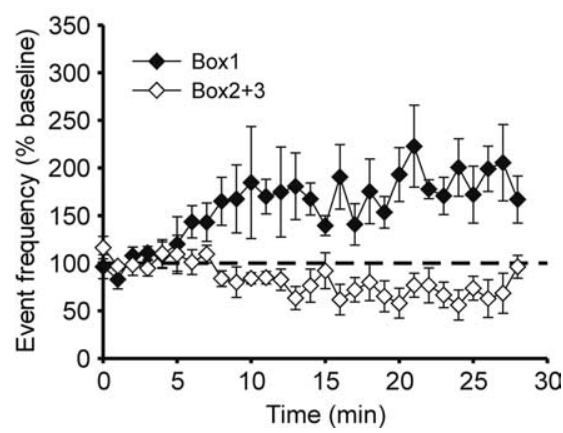

Figure 2. The effect of postsynaptic depolarization is mimicked by BDNF, is prevented by selective antagonists, and does not occur when elevation of intracellular calcium or regulated release is blocked. $A$, Bath perfusion of $20 \mathrm{ng} / \mathrm{ml} \mathrm{BDNF}$ reproduced the effect of postsynaptic depolarization in cells that were recorded at a holding potential of $-70 \mathrm{mV}(n=9 ; \mathbf{O})$. B, K252a prevented the effect of depolarization if it was included in the bath solution $(n=4 ; \triangle)$ but not if it was only included in the pipette solution, thus affecting only the cell being recorded from $(n=6 ; \mathbf{\Delta})$. The latter finding implicates binding of BDNF to presynaptic trkB receptors in the production of the depolarization effect. C, Bath perfusion of an anti-BDNF function-blocking antibody $(n=5 ; \boldsymbol{\nabla})$ or increasing the concentration of EGTA in the pipette solution to $10 \mathrm{~mm}(n=5$; gray squares) prevented the effect of postsynaptic depolarization. $\boldsymbol{D}$, Neurons transfected with Box1 continue to show a postsynaptic depolarization-induced increase in mEPSC frequency $(n=5 ; \diamond)$, whereas neurons transfected with Box $2+3$ do not $(n=5 ; \diamond)$. Error bars indicate \pm SEM.

showing that (1) exogenous application of BDNF reproduced the effect of depolarization, (2) the response depended on activation of presynaptic trkB, (3) BDNF was released into the extracellular medium so that it could diffuse to the presynaptic neuron, and (4) BDNF secretion was dependent on regulated release from the postsynaptic neurons.

As expected from previous studies by ourselves and others (Poo, 2001; Alder et al., 2005), bath application of BDNF elicited an approximate doubling of mEPSC frequency that began within 5 min of the onset of exposure (Fig. 2A), similar to the response that was produced when the presynaptic neuron was held at -40 $\mathrm{mV}$. This experiment also showed that the $-70 \mathrm{mV}$ holding potential did not somehow mask a response to BDNF in Figure 1.

Release of BDNF from the postsynaptic neuron could act both on postsynaptic or presynaptic trkB receptors. Although the change in mEPSC frequency is diagnostic of a presynaptic action, other explanations are possible. To determine this unequivocally, we added the trk inhibitor K252a to the bath or included it in the pipette solution while maintaining the holding potential at -40 $\mathrm{mV}$. The former condition would be expected to affect both presynaptic and postsynaptic receptors, whereas the latter condition would produce inhibition that was confined to the postsynaptic cell. Consistent with our model, bath application of K252a prevented the effect of depolarizing the postsynaptic neuron, whereas postsynaptic application of the inhibitor did not (Fig. $2 B$ ).

To confirm that the increase in mEPSC frequency depended on BDNF released into the extracellular environment, and to also use a manipulation specific to BDNF, we depolarized neurons to $-40 \mathrm{mV}$ but added a function blocking anti-BDNF antibody (Promega, Madison, WI) to the perfusion solution. Under these conditions, mEPSC frequency remained stable throughout the recording (Fig. 2C). To examine the calcium dependence of BDNF release, we increased the EGTA concentration in our pipette solution from $0.2 \mathrm{~mm}$ to $10 \mathrm{~mm}$. This manipulation also prevented the effect of depolarization on mEPSC frequency (Fig. 2C).

To establish that depolarization elicits regulated release of BDNF, we transfected neurons with GFP fusion proteins containing regions of the BDNF prodomain. Transfection with a protein containing amino acids 44-102 of the prodomain [Box 2+3 (Chen et al., 2005)] prevents BDNF interaction with sortilin and, as a result, its regulated release (Chen et al., 2005). Recordings from transfected (GFP-positive) cells showed that depolarization no longer elicited an increase in mEPSC frequency (Fig. 2D). As a control, we transfected with a protein containing amino acids 19-43 of the BDNF prodomain [Box 1 (Chen et al., 2005)] that does not affect BDNF release. For these cells, depolarization elicited the expected response (Fig. 2D).

When examined in aggregate (Fig. 3), the data support a model in which tonic depolarization evokes release of BDNF (Fig. 3B, step 1), which diffuses from the postsynaptic neuron to the presynaptic neuron (Fig. 3B, step 2), binds to presynaptic trkB (Fig. 3B, step 3), which then elevates mEPSC frequency (Fig. 3B, step 4). Manipulations that interfere selectively with these steps (Fig. $3 A$, open bars) prevent the action of depolarization. Manipulations that do not interfere with these steps (Fig. 3A, filled bars) have no effect.

\section{Discussion}

Collectively, our data show that depolarization-dependent release of BDNF from postsynaptic neurons can produce potentiated transmission in their presynaptic partners (Fig. 3B). Disruption of elevation of intracellular calcium, regulated release, diffusion, and presynaptic trkB all prevent the presynaptic response, thus indicating that BDNF fully qualifies as a transsynaptic retrograde signaling molecule. Although activitydependent release of BDNF has been described previously (Schinder and Poo, 2000; Lessmann et al., 2003), we now show that this release can operate at a cell-specific level that does not require the firing of action potentials.

The ability of tonic depolarization to elicit BDNF release is a novel aspect of this study. For reasons described below, we chose $-40 \mathrm{mV}$ as our stimulus, which is approximately what would be achieved by an elevated $\mathrm{K}^{+}$concentration of $10 \mathrm{~mm}$ (Leslie et al., 2001). To examine a potential mediator of this effect, we conducted recordings in which the intracellular concentration of EGTA was increased from $0.2 \mathrm{~mm}$ to $10 \mathrm{~mm}$ so as to blunt increases in intracellular calcium. Calcium influx has been shown 
to play a vital role in triggering the secretion of BDNF as a result of electrical stimulation. In experiments with GFP-tagged BDNF, it was shown that high-frequency electrical stimulation could elicit release of BDNF from glutamatergic synaptic junctions (Hartmann et al., 2001). This secretion could be blocked by AMPA and NMDA antagonists and was shown to require an extracellular calcium influx (Hartmann et al., 2001). In other work, it was suggested that BDNF release was prevented by manipulations that interfered with release of calcium from intracellular stores (Balkowiec and Katz, 2002). How some studies differ from ours, however, is that they find that steady-state depolarization cannot elicit BDNF secretion (Kohara et al., 2001; Kojima et al., 2001; Gartner and Staiger, 2002), a result suggested to occur because the intracellular calcium levels required for BDNF secretion can only be obtained through repeated action potential firing. With TTX in the extracellular bath solution, $\mathrm{Na}$-dependent action potentials are obviously not required for the BDNF secretion that we observe, although Ca-dependent action potentials could theoretically be generated in the dendrites. If this occurred, however, the calcium spikes must have been highly localized because they were not evident in our somatic recordings. Thus, our results indicate instead that when using a physiological method of detection, prolonged tonic depolarization elicits a sufficient elevation of intracellular calcium to induce BDNF secretion.

With moderate depolarization being able to evoke calciumdependent release of BDNF, the question arises as to its origin in vivo. During early development, a source of excitatory input would be both tonically and phasically released GABA (Farrant and Nusser, 2005). It is known that immature neurons undergo a period in which they receive excitatory input via $G_{A B A}$ receptors (Ben-Ari, 2002). A recapitulation of this GABAergic excitation is also seen in newly generated neurons in the dentate gyrus of adult mice (Overstreet Wadiche et al., 2005; Ge et al., 2006). The strength of this input is limited because, even at early postnatal times, the chloride reversal potential is at approximately $-40 \mathrm{mV}$. This capping of excitability has been proposed to be critical for growth-promoting excitation without causing excitotoxicity (Ben-Ari, 2002). It has been shown that this depolarizing GABAergic input can be critical for normal neuronal development (Borodinsky et al., 2003; Ge et al., 2006), and a possible mediator of this effect could be regulated release of BDNF, the expression of which has been shown to be enhanced by GABA application (Berninger et al., 1995). Although it has been reported that depolarization-induced release of BDNF is essentially eliminated by exposure to TTX (Blochl and Thoenen, 1995; Balkowiec and Katz, 2000, 2002; Kojima et al., 2001; Gartner and Staiger, 2002) and would therefore not be expected to occur in response to moderate sustained depolarization, it is possible that the methodology used was not sensitive enough to detect it. We therefore chose to hold cells at $-40 \mathrm{mV}$ and use a change in presynaptic responsiveness as our assay. Our finding that this depolarized holding potential produced a BDNF-dependent alteration in presynaptic activity shows that tonic action potential-
B

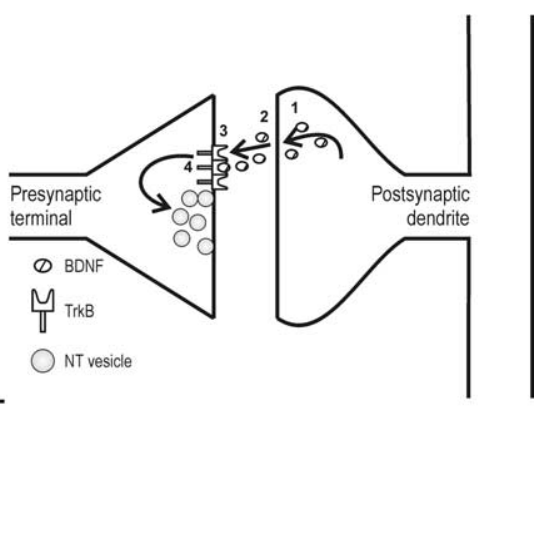

Figure 3. Summary of the different manipulations on the presynaptic action of released BDNF. $\boldsymbol{A}$, Plot of average event regulated release, with a BDNF scavenging antibody to block diffusion and by blocking presynaptic trkB function. Error bars indicate itter-containing vesicle.

independent depolarization can elicit sufficient BDNF release to have functional consequences. Holding the membrane potential at $-70 \mathrm{mV}$ had no effect, ruling out constitutive release of BDNF as an explanation for this phenomenon.

In isolated hippocampal slice preparations, the resting potential in the cell bodies of immature pyramidal neurons has been reported to be approximately $-85 \mathrm{mV}$ in quiescent cells in which activity has been blocked (Leinekugel et al., 1997; Fricker et al., 1999); without blocking activity, this value decreased to $-77 \mathrm{mV}$ (Tyzio et al., 2003). In this case, is the BDNF secretion that we observe likely to occur in vivo? Based on the following observations, we predict that it would. First, we do not expect that cells must be depolarized to $-40 \mathrm{mV}$ to evoke BDNF release. Wholecell voltage clamp of neuronal somata does not produce uniform space clamp of the dendritic processes, and there is electrotonic decay between the site of current injection and the site of BDNF release, so the efficacious membrane potential in the dendrites is going to be more negative than $-40 \mathrm{mV}$. Second, the reverse argument applies that activation of $\mathrm{GABA}_{\mathrm{A}}$ receptors in the dendrites will produce a significantly greater depolarization locally than is measured in the soma, particularly given the high input resistance of immature neurons in which even current through individual GABA receptor channels can evoke action potentials (Serafini et al., 1995). Third, the tonic excitatory inputs are likely to be more prominent in vivo than in an isolated in vitro slice that is constantly being perfused with ACSF. Fourth, there are populations of voltage-gated calcium channels activated at low voltages $(-70$ to $-50 \mathrm{mV})$ comparable to those that elicit BDNF release that contribute to tonic intracellular calcium concentration (Magee et al., 1998). Fifth, GABA excitation itself can activate voltage-gated calcium channels (Ben-Ari, 2002) that could be the actual physiological stimulus that elicits BDNF release. For these reasons, we expect that regulated BDNF secretion of the type we described does occur in the developing hippocampus.

An additional issue with respect to physiological function is whether the effects of released BDNF are restricted to synapses that exhibit a certain level of activity. Work with postnatal day 
12-13 hippocampal slices failed to detect any effect of exogenously applied BDNF unless the presynaptic afferents were driven at high frequency (Gottschalk et al., 1998). In a related way, it has also been shown that presynaptic depolarization dramatically enhances the efficacy of BDNF at Xenopus neuromuscular synapses (Boulanger and Poo, 1999). In contrast, it has been shown in cultured hippocampal neurons that synapses with low release probability were preferentially affected by exogenously applied BDNF (Berninger et al., 1999). An interesting way to reconcile these findings is that nascent synapses are particularly susceptible to BDNF, but as they mature, they require coincident depolarization in order for effects to become manifest.

Previous work on BDNF release has been accomplished with a variety of tools and approaches (Lessmann et al., 2003). A second goal of this study was to bring together these diverse aspects by studying release of endogenous BDNF at the single-cell level and addressing the question of whether BDNF satisfies the criteria to be a retrograde messenger. In a recent review by Alger (2002), these criteria were enumerated based on retrograde transmission by endocannabinoids. Although the presynaptic actions of BDNF occur on a slower time scale than endocannabinoids, the approach is relevant nonetheless because functional effects of endogenous BDNF released from single cells have not been shown directly. Although studies of overexpressed BDNF have provided invaluable information (Lessmann et al., 2003), they can be criticized as artificial because release may be a consequence of excessive BDNF production. We therefore used the well described increase in mEPSC frequency as an indicator of endogenous $\mathrm{BDNF}$ release. By depolarizing a neuron to $-40 \mathrm{mV}$ and recording the frequency of incoming mEPSCs, we showed that a physiological stimulus can elicit a functional response. By using selective blockers of BDNF, as well as a disruption of regulated release, we identified the mediator of this effect as BDNF, fulfilling the criteria for retrograde transmission.

Regulated release of BDNF has been shown to be critical for functions ranging from neurite outgrowth and spine formation (McAllister et al., 1996; Tyler and Pozzo-Miller, 2001; Horch and Katz, 2002; Jin et al., 2003) to short- and long-lasting forms of synaptic plasticity (Nagappan and Lu, 2005) to learning and cognition (Tyler et al., 2002; Egan et al., 2003; Hariri et al., 2003; Rybakowski et al., 2003). The mechanisms of this release are gradually being better understood as the molecular interactions responsible for regulated release are identified (Chen et al., 2005; Lou et al., 2005), but numerous functional issues remain to be clarified. In particular, it will be important to examine the relative roles of anterograde and retrograde BDNF signaling, both of which unequivocally occur but which may have different stimulus selectivities and functional outcomes.

\section{References}

Alder J, Thakker-Varia S, Crozier RA, Shaheen A, Plummer MR, Black IB (2005) Early presynaptic and late postsynaptic components contribute independently to brain-derived neurotrophic factor-induced synaptic plasticity. J Neurosci 25:3080-3085.

Alger BE (2002) Retrograde signaling in the regulation of synaptic transmission: focus on endocannabinoids. Prog Neurobiol $68: 247-286$.

Balkowiec A, Katz DM (2000) Activity-dependent release of endogenous brain-derived neurotrophic factor from primary sensory neurons detected by ELISA in situ. J Neurosci 20:7417-7423.

Balkowiec A, Katz DM (2002) Cellular mechanisms regulating activitydependent release of native brain-derived neurotrophic factor from hippocampal neurons. J Neurosci 22:10399-10407.

Ben-Ari Y (2002) Excitatory actions of GABA during development: the nature of the nurture. Nat Rev Neurosci 3:728-739.

Berninger B, Marty S, Zafra F, da Penha Berzaghi M, Thoenen H, Lindholm D
(1995) GABAergic stimulation switches from enhancing to repressing BDNF expression in rat hippocampal neurons during maturation in vitro. Development 121:2327-2335.

Berninger B, Schinder AF, Poo MM (1999) Synaptic reliability correlates with reduced susceptibility to synaptic potentiation by brain-derived neurotrophic factor. Learn Mem 6:232-242.

Blochl A, Thoenen H (1995) Characterization of nerve growth factor (NGF) release from hippocampal neurons: evidence for a constitutive and an unconventional sodium-dependent regulated pathway. Eur J Neurosci $7: 1220-1228$

Borodinsky LN, O’Leary D, Neale JH, Vicini S, Coso OA, Fiszman ML (2003) GABA-induced neurite outgrowth of cerebellar granule cells is mediated by GABA(A) receptor activation, calcium influx and CaMKII and erk1/2 pathways. J Neurochem 84:1411-1420.

Boulanger L, Poo MM (1999) Presynaptic depolarization facilitates neurotrophin-induced synaptic potentiation. Nat Neurosci 2:346-351.

Bouron A (2001) Modulation of spontaneous quantal release of neurotransmitters in the hippocampus. Prog Neurobiol 63:613-635.

Chao MV (2003) Neurotrophins and their receptors: a convergence point for many signalling pathways. Nat Rev Neurosci 4:299-309.

Chen ZY, Ieraci A, Teng H, Dall H, Meng CX, Herrera DG, Nykjaer A, Hempstead BL, Lee FS (2005) Sortilin controls intracellular sorting of brainderived neurotrophic factor to the regulated secretory pathway. J Neurosci 25:6156-6166.

Du J, Feng L, Zaitsev E, Je HS, Liu XW, Lu B (2003) Regulation of TrkB receptor tyrosine kinase and its internalization by neuronal activity and Ca2+ influx. J Cell Biol 163:385-395.

Du JL, Poo MM (2004) Rapid BDNF-induced retrograde synaptic modification in a developing retinotectal system. Nature 429:878-883.

Egan MF, Kojima M, Callicott JH, Goldberg TE, Kolachana BS, Bertolino A, Zaitsev E, Gold B, Goldman D, Dean M, Lu B, Weinberger DR (2003) The BDNF val66met polymorphism affects activity-dependent secretion of BDNF and human memory and hippocampal function. Cell 112:257-269.

Farrant M, Nusser Z (2005) Variations on an inhibitory theme: phasic and tonic activation of GABA(A) receptors. Nat Rev Neurosci 6:215-229.

Fitzsimonds RM, Poo MM (1998) ) Retrograde signaling in the development and modification of synapses. Physiol Rev 78:143-170.

Fricker D, Verheugen JA, Miles R (1999) Cell-attached measurements of the firing threshold of rat hippocampal neurones. J Physiol (Lond) 517:791-804

Gartner A, Staiger V (2002) Neurotrophin secretion from hippocampal neurons evoked by long-term-potentiation-inducing electrical stimulation patterns. Proc Natl Acad Sci USA 99:6386-6391.

Ge S, Goh EL, Sailor KA, Kitabatake Y, Ming GL, Song H (2006) GABA regulates synaptic integration of newly generated neurons in the adult brain. Nature 439:589-593.

Ginty DD, Segal RA (2002) Retrograde neurotrophin signaling: Trk-ing along the axon. Curr Opin Neurobiol 12:268-274.

Gottschalk W, Pozzo-Miller LD, Figurov A, Lu B (1998) Presynaptic modulation of synaptic transmission and plasticity by brain-derived neurotrophic factor in the developing hippocampus. J Neurosci 18:6830-6839.

Hariri AR, Goldberg TE, Mattay VS, Kolachana BS, Callicott JH, Egan MF, Weinberger DR (2003) Brain-derived neurotrophic factor val66met polymorphism affects human memory-related hippocampal activity and predicts memory performance. J Neurosci 23:6690-6694.

Hartmann M, Heumann R, Lessmann V (2001) Synaptic secretion of BDNF after high-frequency stimulation of glutamatergic synapses . EMBO J 20:5887-5897.

Horch HW, Katz LC (2002) BDNF release from single cells elicits local dendritic growth in nearby neurons. Nat Neurosci 5:1177-1184.

Jin X, Hu H, Mathers PH, Agmon A (2003) Brain-derived neurotrophic factor mediates activity-dependent dendritic growth in nonpyramidal neocortical interneurons in developing organotypic cultures. J Neurosci 23:5662-5673.

Kohara K, Kitamura A, Morishima M, Tsumoto T (2001) Activitydependent transfer of brain-derived neurotrophic factor to postsynaptic neurons. Science 291:2419-2423.

Kojima M, Takei N, Numakawa T, Ishikawa Y, Suzuki S, Matsumoto T, Katoh-Semba R, Nawa H, Hatanaka H (2001) Biological characterization and optical imaging of brain-derived neurotrophic factor-green fluorescent protein suggest an activity-dependent local release of brain- 
derived neurotrophic factor in neurites of cultured hippocampal neurons. J Neurosci Res 64:1-10.

Leinekugel X, Medina I, Khalilov I, Ben-Ari Y, Khazipov R (1997) Ca2+ oscillations mediated by the synergistic excitatory actions of GABA(A) and NMDA receptors in the neonatal hippocampus. Neuron 18:243-255.

Leslie KR, Nelson SB, Turrigiano GG (2001) Postsynaptic depolarization scales quantal amplitude in cortical pyramidal neurons. J Neurosci 21: $\mathrm{RC} 170(1-6)$.

Lessmann V (1998) Neurotrophin-dependent modulation of glutamatergic synaptic transmission in the mammalian CNS. Gen Pharmacol 31:667-674.

Lessmann V, Gottmann K, Malcangio M (2003) Neurotrophin secretion: current facts and future prospects. Prog Neurobiol 69:341-374.

Levine ES, Dreyfus CF, Black IB, Plummer MR (1995) Brain-derived neurotrophic factor rapidly enhances synaptic transmission in hippocampal neurons via postsynaptic tyrosine kinase receptors. Proc Natl Acad Sci USA 92:8074-8077.

Lou H, Kim SK, Zaitsev E, Snell CR, Lu B, Loh YP (2005) Sorting and activity-dependent secretion of BDNF require interaction of a specific motif with the sorting receptor carboxypeptidase E. Neuron 45:245-255.

Lu B, Gottschalk W (2000) Modulation of hippocampal synaptic transmission and plasticity by neurotrophins. Prog Brain Res 128:231-241.

Magee J, Hoffman D, Colbert C, Johnston D (1998) Electrical and calcium signaling in dendrites of hippocampal pyramidal neurons. Annu Rev Physiol 60:327-346.

McAllister AK, Katz LC, Lo DC (1996) Neurotrophin regulation of cortical dendritic growth requires activity. Neuron 17:1057-1064.

Nagappan G, Lu B (2005) Activity-dependent modulation of the BDNF re- ceptor TrkB: mechanisms and implications. Trends Neurosci 28:464-471.

Overstreet Wadiche L, Bromberg DA, Bensen AL, Westbrook GL (2005) GABAergic signaling to newborn neurons in dentate gyrus. J Neurophysiol 94:4528-4532.

Poo MM (2001) Neurotrophins as synaptic modulators. Nat Rev Neurosci 2:24-32.

Rybakowski JK, Borkowska A, Czerski PM, Skibinska M, Hauser J (2003) Polymorphism of the brain-derived neurotrophic factor gene and performance on a cognitive prefrontal test in bipolar patients. Bipolar Disord 5:468-472.

Schinder AF, Poo M (2000) The neurotrophin hypothesis for synaptic plasticity. Trends Neurosci 23:639-645.

Schmidt JT (2004) Activity-driven sharpening of the retinotectal projection: the search for retrograde synaptic signaling pathways. J Neurobiol 59:114-133.

Serafini R, Valeyev AY, Barker JL, Poulter MO (1995) Depolarizing GABAactivated $\mathrm{Cl}-$ channels in embryonic rat spinal and olfactory bulb cells. J Physiol (Lond) 488:371-386.

Tyler WJ, Pozzo-Miller LD (2001) BDNF enhances quantal neurotransmitter release and increases the number of docked vesicles at the active zones of hippocampal excitatory synapses. J Neurosci 21:4249-4258.

Tyler WJ, Alonso M, Bramham CR, Pozzo-Miller LD (2002) From acquisition to consolidation: on the role of brain-derived neurotrophic factor signaling in hippocampal-dependent learning. Learn Mem 9:224-237.

Tyzio R, Ivanov A, Bernard C, Holmes GL, Ben-Ari Y, Khazipov R (2003) Membrane potential of CA3 hippocampal pyramidal cells during postnatal development. J Neurophysiol 90:2964-2972. 